oximetry and intranasal administration of oxygen are thus advisable during the procedure.

1 Schiller KFR, Cotton PB, Salmon PR. The hazards of digestive fibre endoscopy. A survey of British experience. Gut 1972;13:1027.

2 Woods SDS, Chung SCS, Leung JWC, Chan ACW, Li AKC. Hypoxia and tachycardia during endoscopic retrograde cholangiopancreatography: detection by pulse oximetry. Gastrointest Endosc (in press).
3 Lieberman DA, Wuerker CK, Katon RM. Cardiopulmonary risk of esophagogastroduodenoscopy. Gastroenterology 1985;88:458-72.

Rozen P, Oppenheim D, Ratan J, Laniado S, Gilat T. Arterial oxygen tension changes in elderly patients undergoing upper gastrointestinal endoscopy 1. Possible causes. Scand f Gastroenterol 1979;14:577-81.

5 Hoffman JIE, Buckberg JD. Regional myocardial ischaemia - causes, prediction and prevention. Vasc Surg 1974;8:115-30.

(Accepted 15 September 1989)

\section{The oesophagus in lichen planus: an endoscopic study}

\author{
Christopher M Dickens, David Heseltine, \\ Shernaz Walton, John R Bennett
}

\section{Hull Royal Infirmary, Hull, North Humberside} HU3 2JZ

Christopher M Dickens, MB, senior house officer, department of medicine David Heseltine, MRCP, senior registrar, department of medicine and gastroenterology Shernaz Walton, MD, senior registrar, department of dermatology

John R Bennett, MD, consultant gastroenterologist

Correspondence and requests for reprints to: $\mathrm{Dr}$ Bennett.

BrMed f 1990;300:84 scopy would benefit all patients with the disease.

\section{Patients, methods, and results}

Lichen planus is a common condition of unknown aetiology. Oral disease is common, occurring in 30 $70 \%$ of cases, but premalignant oesophageal disease is considered to be extremely rare ${ }^{1-4}$ (only about 10 cases have been reported). Oesophageal disease may result in dysphagia $^{1-4}$ and the formation of benign strictures. ${ }^{2+}$ In view of the increased risk of malignant change with oral lichen planus ${ }^{12}$ chronic erosive changes of lichen planus in the oesophagus may also be premalignant, although no such cases have been reported. We carried out a study to establish the prevalence of oesophageal lichen planus and to determine whether routine endo-

We selected for study all patients presenting to the dermatology department at this hospital with active lichen planus between October 1987 and May 1989. We excluded patients who were taking drugs that might produce oesophageal changes or reduce any such changes due to lichen planus and those who were unfit for endoscopy owing to cardiorespiratory disease. Altogether five women and 14 men aged 20 to 66 (mean age 44) were given an endoscopic examination by a single observer. Each patient was questioned about the duration of the disease and the presence or absence of any symptoms of dysphagia, dyspepsia, or regurgitation of acid. An examination was performed to establish the type of cutaneous disease and whether there was any oral disease.

Four patients did not have any visible skin disease, 13 had papular lesions, one had hypertrophic lichen planus, and one had bullous lichen planus. Nine patients did not have any visible oral disease, three had Wickham's striae, four had white plaques, one had disease of the lips, one had minor erosive changes, and one had severe erosive oropharyngeal disease associated with dysphagia.

Five patients had oesophageal lichen planus, of whom four had subtle papular lesions (visible only in the lower third in three cases and throughout the whole oesophagus in one). These changes were different from those that occur in reflux oesophagitis in that superficial layers tended to strip off at biopsy. The patient with dysphagia had severe erosive changes in the whole oesophageal mucosa (figure). A study of the $\mathrm{pH}$ of the oesophagus showed acid reflux well within the normal range. Four of the five patients with oesophageal lichen planus also had oral disease. Histological examination of biopsy specimens of the oesophageal mucosa from the five patients showed submucosal lymphocytic infiltrates consistent with, but not diagnostic of, lichen planus $^{1}$ and quite different from changes induced by acid reflux. The patient with severe oesophageal disease showed a heavy infiltrate of polymorphs, lymphocytes, and plasma cells in the fibromuscular tissue underlying the necrotic areas.

\section{Comment}

We believe this to be the first study attempting to determine the prevalence of oesophageal lichen planus. Though the numbers are small, these results suggest that the prevalence has been greatly underestimated previously: we found that a quarter of people with lichen planus have oesophageal disease. In oral lichen planus $0 \cdot 8-10 \%$ of cases undergo malignant change. If these figures also apply to oesophageal disease a considerable group of people would seem to be at risk of developing carcinoma of the oesophagus, which might be prevented by early treatment.

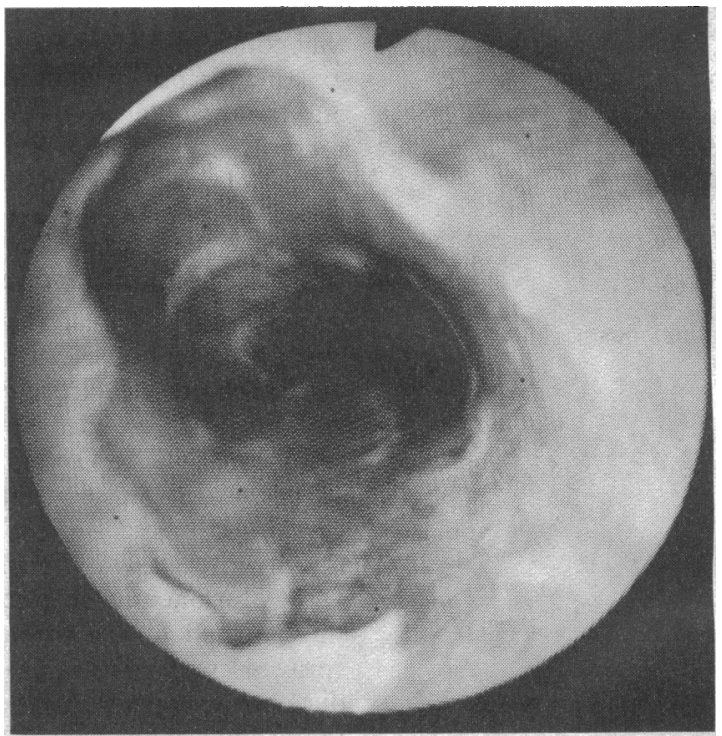

Severe erosive lichen planus of oesophagus seen on endoscopy

We conclude that patients presenting with lichen planus should be questioned about gastrointestinal symptoms and if oesophageal disease is suspected oesophagoscopy should be performed. When severe oesophageal disease is found steroid treatment should probably be started to reduce the symptoms and any strictures $^{124}$ and possibly to decrease any risk of malignant transformation. The benefits of steroid treatment should be confirmed by controlled investigation of a large number of patients.

We thank Dr E H Wyatt and Dr K Keczkes, consultants in dermatology at this hospital, for giving us permission to study their patients and Dr D Piercy, who performed the histological studies.

1 Sheehan-Dare RA, Cotterill JA, Simmons AV. Oesophageal lichen planus. Brf Dermatol 1986;115:729-30.

Jobard-Drobacheff C, Blae D, Quencez E, et al. Lichen planus of the oesophagus. Clin Exp Dermatol 1988;13:38-41.

3 aer

4 Al-Shihabi BMS, Jackson JM. Dysphagia due to pharyngeal and oesophageal lichen planus. F Laryngol Otol 1982;96:567-71.

5 Altman J, Perry H. The variations and course of lichen planus. Arch Dermato $1961 ; 84: 47-59$

(Accepted 2 October 1989) 